\title{
A problematização do erro e a concepção cartesiana de liberdade ${ }^{1}$
}

\author{
DANIELE PACHECO DO NASCIMENTO *
}

RESUMO Na Quarta Meditação, a questão metafísica acerca da possibilidade do erro é introduzida quando Descartes problematiza como seria possível um criador perfeito, sumamente bom, criador de todas as coisas e de toda a verdade, gerar criaturas que erram. Considerando a Regra Geral da verdade, segundo a qual toda ideia clara e distinta é verdadeira e, assim, descartando a hipótese do Deus enganador, que seria a causa do erro sistemático da substância pensante, a questão envolvida é: por que a substância pensante não se restringe a realizar juízos apenas sobre as ideias que são claras e distintas e a suspender o juízo ao deparar-se com ideias obscuras e confusas? Paralelo à questão metafísica, Descartes se ocupa da questão epistemológica quando pretende explicar o que ocorre com a operação cognitiva da substância pensante quando ela erra. Se suspendesse o juízo sobre o que percebe obscura e confusamente, a substância pensante não cometeria o erro. Há, no entanto, dois casos distintos em que,embora não haja evidências da verdade de uma ideia, isto é, embora a ideia não seja clara e distinta, a substância pensante não suspende o juízo: 1) Quando opta pela crença na verdade da ideia que lhe parece mais provável e realiza um juízo que pode ser equivocado. 2) Quando, embora uma ideia seja percebida como clara e distinta, trata-se, de fato, de uma ideia obscura e confusa. O segundo caso parece mais relevante na medida em que diz respeito ao erro no sentido estrito, pois envolve não saber estar errando. A questão a qual nos deparamos e pretendemos tratar é: se, para Descartes, Deus é veraz e por isso há a garantia da Regra Geral da Verdade e, se não faz parte de Seus desígnios que nos enganemos, então como seria possível a efetivação do erro?

PALAVRAS-ChAVE erro;vontade; entendimento; liberdade.

* Mestranda / UFRJ / Programa de Pós-Graduação Lógica e Metafísica (PPGLM) Bolsista (CAPES)

1 O presente texto possui uma interpretação alinhada com a de Ethel Menezes Rocha (UFRJ) em seu artigo denominado Criador perfeito e criaturas que erram (ROCHA, 2013). 
NA QUARTA MEDITAÇÃo, Descartes problematiza a questão do erro: considerando a bondade e perfeição divina, junto ao fato de ser Deus o criador de todas as coisas e de toda a verdade, ele se pergunta como Este ser poderia gerar criaturas que erram e o que ocorre na substância pensante quando ela erra. Descartes considera duas questões relacionadas à questão do erro: a questão epistêmica, abordando qual seria a imperfeição humana responsável pela operacionalização do erro, considerando quais seriam as faculdades que se conjugam resultando no erro da substância pensante e a questão metafísica, deliberando como seria possível que um ser perfeito, infinito esumamente bom, que tudo pode, tudo sabe, tudo quer e faz, cria uma substância que erra? A questão metafísica acerca do erro, portanto, é a mesma questão colocada por diferentes filósofos que apresentam uma teodiceia: ou Deus não poderia criar o bem, ou não saberia criar o bem ou, ainda, não desejaria criar o bem e por isso cria seres que erram. Uma contrariedade aqui deve ser considerada: Deus não somente quer o bem (a verdade), como sabe o que é o bem e também, efetivamente, cria o bem.

Descartes começa averiguando ${ }^{2}$ a questão metafísica ponderando explicações dadas pela tradição e aceitando parcialmente cada uma delas. Considerando a Regra Geral da verdade (toda ideia clara e distinta é verdadeira) e descartada a hipótese do Deus enganador (considerando a prova da existência de Deus veraz), para que não haja o erro, a substância pensante deveria, a princípio, realizar juízos apenas sobre as ideias 3 que lhe aparecem como claras e distintas e suspender o juízo perante as obscuras e confusas $^{4}$. Isto aparentemente seria o suficiente para evitar o erro. Mas não é o que

2 DESCARTES, Meditação Quarta, p. 124.

Sempre que possível, optamos, em nossas citações, pela tradução de J. Guinsburg e Bento Prado Júnior (1973).

3 O termo "ideia" designa o ato do pensamento, bem como o conteúdo desse ato.

4 Consideramos importante logo aqui ressaltar que perceber algo como obscuro e confuso é diferente de perceber obscura e confusamente, porque perceber como obscuro é perceber que não se conhece o que está sendo percebido, enquanto perceber obscura e confusamente não envolve saber que o que está sendo alvo da percepção é algo que não se conhece. É possível que se perceba obscura e confusamente algo que nos apareça, entretanto, como se fosse uma percepção clara e distinta. Toda nossa reconstrução da argumentação cartesiana em torno da questão do erro terá como base essa distinção entre perceber obscura e confusamente algo e perceber que uma ideia é obscura e 
ocorre. Nem sempre a substância pensante suspende o juízo quando diante de ideias obscuras e confusas. Há dois casos em que isso ocorre: quando na urgência da vida sabemos que estamos diante de uma ideia obscura e confusa, mas mesmo assim optamos por afirmá-la (e esse é um sentido fraco de erro, porque aqui sabemos que podemos estar errando); e quando uma ideia nos aparece como clara e distinta, mas de fato é uma ideia obscura e confusa (e esse é o sentido forte de erro na medida em que envolve não saber que está errando. Esse é o caso de erro que interessa a Descartes).

Uma das soluções tradicionais para a questão metafísica do erro, examinada por Descartes, é a tese de que Deus não poderia ser a causa do erro, pois o erro não existe como uma coisa real: o mal que é o erro não teria nenhuma densidade ontológica, logo Deus não poderia ser a causa do erro. Ele aceita desse argumento o fato de que o erro não é, efetivamente, real, sendo "apenas uma carência5", isso porque, para Descartes, Deus cria substâncias e modos e o erro não é uma substância e nem um modo ${ }^{6}$ da mesma. Porém, embora o erro não seja efetivamente real, há de se considerar que o erro é proveniente de algum ser que erra, pois nada provém do nada, de modo que esse ser que erra foi criado por Deus. Seria, portanto, o Ser infinito responsável pelo erro?

Outra solução da questão, dada pela tradição, está relacionada à incompreensibilidade dos propósitos divinos. Ao analisar que o erro não é real, Descartes faz uma discussão entre negação e privação e na sua concepção o erro não ocorre por algo que Deus nos nega (certas ideias), mas sim provém de algo que deveríamos ter, sendo criaturas com operações cognitivas, e não temos (uma privação de certas ideias claras e distintas), pois conforme o filósofo

(...) o erro não é pura negação, isto é, não é simplesmente a carência ou falta de alguma perfeição que me não é devida, mas antes é uma privação de algum conhecimento que parece que eu deveria possuir ${ }^{7}$.

confusa ou perceber como clara e distinta uma ideia que efetivamente não é clara e distinta e sim obscura e confusa.

6 Não existe, por exemplo, o erro, a virtude, em Descartes: existe o homem que erra, o homem virtuoso, etc. 
Descartes considera que se Deus criou a substância pensante com faculdades cognitivas, criou-a podendo conhecer. Assim, o fato de errarmos significaria que Deus privou a substância pensante daquilo que ela deveria ter, a saber, o conhecimento.

Descartes, portanto, entende que o erro não é relativo às ideias que não temos, mas sim às ideias que temos e são obscuras e confusas (embora, como veremos, apareçam como claras e distintas). Para ele, Deus nos criou sem algumas ideias porque somos finitos e não podemos ter todas as ideias - o que não envolve nenhum erro: não podemos crer em ideias que não temos. Assim, o que envolve o erro são as ideias obscuras e confusas: o que acontece é que fomos criados com faculdades cognitivas, mas, para o filósofo, das ideias quenos aparecem como claras e distintas, produzidas por essas faculdades, nem todas são, de fato, claras e distintas. Assim, para ele, Deus nos privou $^{8}$ de ideias claras e distintas que poderíamos ter. O que, segundo Descartes, reintroduz a questão do erro já que, sendo sumamente bom, Deus poderia nos ter criado de forma que tivéssemos efetivamente apenas ideias claras e distintas.

O que parece é que Deus criou criaturas com operações para conhecer e que deveriam operar dessa forma (verdadeiramente conhecer), mas somos de maneira tal que não somos efetivamente assim. No entanto, Descartes considera que dada a natureza de Deus, Suas criaturas não podem ser criadas com “alguma faculdade imperfeita em seu gênero ${ }^{9 "}$. Então, por qual razão Deus nos teria feito desse modo, ou seja, por qual motivo não fomos criados optando sempre pelo certo e, ao invés disso, muitas vezes erramos, optando pelo falso e não pelo verdadeiro ou pelo mal em lugar do bem? Para tal questão, na tentativa de uma explicação, a tradição alega que não é possível saber os propósitos divinos dada impossibilidade de conhecer Sua natureza, o que significa que não sabemos porque Deus não nos criou de tal forma que tivéssemos apenas ideias claras e distintas. Descartes não aceita inteiramente essa resposta da tradição alegando que embora, como afirma a tradição, não seja possível compreender a natureza divina (isto é, conhecer todas as Suas propriedades), “porque obviamente é da natureza do infinito que não seja compreendido por nós, que somos finitos ${ }^{10 ",}$

8 por isso é uma privação e não uma negação

9 DESCARTES, Meditação Quarta, p. 124.

10 DESCARTES, Princípios da Filosofia, p. 39. 
nós podemos conhecera natureza divina (temos uma ideia clara e distinta de Deus). Assim, de acordo com Descartes,

sabendo já que minha natureza é extremamente fraca e limitada, e, ao contrário, que a de Deus é imensa, incompreensível e infinita, não mais tenho dificuldade em reconhecer que há uma infinidade de coisas em sua potência cujas causas ultrapassam o alcance de meu espírito ${ }^{11}$.

No desenvolvimento da problematização, segue-se que não compreendemos os propósitos divinos, mas não porque não conhecemos a natureza de Deus e sim em virtude da inexistência dos mesmos, ao menos no mundo físico. Na Quarta Meditação ${ }^{12}$ Descartes explica, como vimos na citação acima, que ao contrário de sua natureza “fraca e limitada”, a natureza de Deus “é imensa, incompreensível e infinita”, e, reconhece haver, em função disso, uma infinidade de coisas na potência divina cujas causas ultrapassam o alcance de seu espírito e, em suas palavras, “(...) esta única razão é suficiente para persuadir-me de que todo esse gênero de causas que se costuma tirar do fim não é de uso algum nas coisas físicas ou naturais” ${ }^{13}$. Sobre esta última parte,adefesa de Descartes é a de que não há causas finais e nem teleológicas para a explicação do mundo físico e das coisas naturais. Ao banir a finalidade e quaisquer propósitos na natureza, de acordo com Cottingham, Descartes busca, como efeito de sua tese, “subordinar a cosmologia à física ${ }^{14 ", ~ a s s i m, ~}$

[n]ão se invocam atos criadores especiais ou propósitos divinos (...); em vez disso, o universo é como uma máquina cujas operações se dão automaticamente, em conformidade com as leis da matéria em movimento. Isso não significa usurpar o lugar de Deus: Descartes muitas vezes enfatiza, tanto em Le monde quanto, ainda com mais ênfase, nos Princípios de filosofia, que as leis uniformes do movimento funcionam devido à força e à constância da deidade (ver Princípios, Parte 11, art. 36). A cosmologia cartesiana tem, no entanto, um caráter austero e impessoal, se comparada à criação especial descrita no Gênese, em que o homem é a peça central e o propósito maior(... ${ }^{15}$.

\footnotetext{
11 DESCARTES, Meditação Quarta, p. 125.

12 DESCARTES, Meditação Quarta, p. 125.

13 DESCARTES, Meditação Quarta, p. 125.

14 COTTINGHAM, Dicionário Descartes, p. 46.

15 COTTINGHAM, Dicionário Descartes, p. 46.
} 
Sobre esta tese cartesiana, ao não ser possível conhecer os propósitos divinos, dada a inexistência dos mesmos, Descartes se coloca contra a tese tradicional aristotélica, a saber, resumidamente, a tese que sustenta que cada coisa existente no mundo existe para um determinado fim e que conhecer algo é conhecer suas causas e o fim é uma dessas causas. Objetando a tradição, Descartes defende a inexistência de propósitos, não só nas coisas físicas, mas em absolutamente tudo, uma vez que Deus é indiferente (embora seja uma indiferença positiva) e arbitrário. Resumidamente, Deus é indiferente porque em seus atos não há quaisquer necessidades: em Sua supremacia, Ele não escolhe entre x ou não x e, segundo Descartes, "não podemos entendê-lo de outra forma senão como produzindo tudo por uma única ação ${ }^{16 ", ~ a l e ́ m ~ d i s s o, ~ n a d a ~ q u e ~ D e u s ~}$ cria é para a Sua satisfação, pois nada falta a Deus, logo não há interesses na criação divina, daí podemos afirmar tratar-se de uma indiferença positiva. Além de criar por indiferença, Seu poder de ação é absoluto e infinito, não havendo nada que oriente a vontade divina, mas para Descartes,

Com efeito, embora Deus seja indiferente a todas as coisas, no entanto, é de maneira necessária que ele as decretou assim, pois ele quis necessariamente o melhor, embora tenha sido por sua vontade que ele o tenha feito tal. Não deveríamos dissociar aqui necessidade e indiferença nos decretos de Deus: embora ele tenha feito tudo com a mais inteira indiferença, no entanto ele o fez ao mesmo tempo com a mais inteira necessidade $(. . .)^{17}$

Deus cria por indiferença e essa indiferença é positiva, no sistema cartesiano. É importante destacar que no caso da substância pensante finita, a indiferença é negativa, porque nos falta o conhecimento, diferentemente do que acontece com Deus, cuja indiferença é positiva, o que significa que Ele possui uma potência infinita e, sendo absoluto, sabe todas as coisas e decide indiferentemente. Assim, não há propósitos externos no ato de Deus criar o mundo: Ele não tem interesses em seus atos, ou seja, nada determina Sua ação. Desse modo, Deus não precisa escolher absolutamente nada e essa Sua indiferença positiva envolve necessidade, como podemos entender, conforme a citação acima.

16 DESCARTES. Textos de Descartes sobre a livre criação das verdades eternas: Extratos da Conversação com Burman, Sobre os Princípios da Filosofia. Traduo de Marcos AndrGleizer, p. 218.

17 DESCARTES. Textos de Descartes sobre a livre criação das verdades eternas: Extratos da Conversação com Burman, Sobre os Princípios da Filosofia. Traduo deMarcos AndrGleizer, p. 219. 
Nesse contexto, é através do conhecimento da natureza de Deus que conhecemos que o que Ele faz é o melhor, não se tratando, como se defende na Escola, de haver uma opção do melhor como uma escolha, afinal para Descartes, é

impossível que uma tal ideia tenha precedido a determinação da vontade de Deus por uma prioridade de ordem, de natureza, ou de razão raciocinada, como a nomeiam na Escola, de sorte que essa ideia do bem tenha levado Deus a eleger um de preferência ao outro. Por exemplo, não foi por ter visto que era melhor que o mundo fosse criado no tempo do que desde a eternidade que ele quis criá-lo no tempo; e ele não quis que os três ângulos de um triângulo fossem iguais a dois retos porque soube que isto não podia ser feito de outra maneira, etc. Mas, ao contrário, é porque ele quis criar o mundo no tempo que é melhor assim do que se ele tivesse sido criado desde a eternidade; e visto que ele quis que os três ângulos do triângulo fossem necessariamente iguais a dois retos, é agora verdade que isto é assim e não pode ser de outra maneira, e assim de todas as outras coisas ${ }^{18}$.

Podemos entender que é necessário que Deus crie as coisas como Ele cria, porque sendo perfeito e só concebendo, dada Sua perfeição, o mais perfeito, não há opções a serem consideradas em seus atos de criação. Não existe, então, a possibilidade, dada perfeição e indiferença positiva de Deus de que ele crie algo que não seja o melhor, mas não em função de uma escolha entre $\mathrm{x}$ e não-x, como mencionado, mas porque no pensamento de Deus (e Ele é puro pensamento) não há envolvida nenhuma "preferência ou prioridade entre seu entendimento e sua vontade. (...) não há nele senão uma única ação, toda simples e toda pura' ${ }^{19 "}$, pois para Descartes, em Deus, ver e querer são o mesmo, assim como "é uma mesma coisa querer, entender e criar, sem que um preceda o outro nem mesmo logicamente ${ }^{20 "}$

Voltando para outra explicação considerada,visando a solução da questão do erro,pela tradição, examinada por Descartes, temos a explicação que recorre ao conceito de liberdade segundo o argumento tradicional cristão: Deus, em sua suma bondade, cria

18 DESCARTES. Textos de Descartes sobre a livre criação das verdades eternas: Respostas às Sextas Objeções, Ponto 6. Traduo de Marcos AndrGleizer, p. 212.

19 DESCARTES. Textos de Descartes sobre a livre criação das verdades eternas: Extratos da Carta ao Padre Mesland de 2 de maio de 1644. Traduo de Marcos AndrGleizer, p. 214.

20 DESCARTES. Textos de Descartes sobre a livre criação das verdades eternas: Extratos da Carta ao Padre Mersenne de 27 de maio de 1630. Traduo de Marcos AndrGleizer, p. 210. 
homens livres de maneira tal que estes poderiam, com liberdade, fazer uma escolha entre dois opostos. Assim o responsável pelo erro seria o ser que erra ao escolher o falso e não o verdadeiro ou que escolhe o mal e não o bem, ou seja, a criatura e não Deus. Mais uma vez, Descartes aceita parcialmente o argumento, pois concorda que Deus criou os homens livres, mas isso não significa criar seres que erram: Deus poderia ter criado seres que podem errar, isto é, livres, por poderem escolher entre dois opostos, sem que nunca errassem. Deus poderia ter criado seres tais que todas as vezes em que estivessem diante de uma decisão optassem sempre pelo certo, embora tivessem o poder de optar pelo errado (sem saber que erravam). Mas como não é isso o que Deus fez, no caso dos homens ${ }^{21}$, não estaria isento da responsabilidade pelo erro humano.

Depois de examinar respostas tradicionais à questão metafísica do erro, Descartes apresenta em que consiste sua posição a esse respeito: é possível explicar porque um ser perfeito cria seres que erram se atentarmos para o fato de que o homem não é o centro da criação divina e embora Deus seja justo e bom, esses atributos não estão relacionados em especial aos homens perante as outras criaturas. No caso dos homens, conforme Descartes, a possibilidade do erro se dá porque são os seres que podem errar e erram, enquanto os anjos são tais que podem errar e não erram e há os animais sem razão que, segundo Descartes afirma para Mesland, evidentemente “(...) não são livres, pois eles não têm essa potência positiva de se determinar; mas é neles uma pura negação, de não serem forçados nem limitados ${ }^{22}$." Neste contexto, nem sempre o que é justo para Deus é considerado da mesma forma pelos homens. Podemos compreender que Deus não criou todas as coisas para o benefício de uma única criatura, afinal a criação divina é realizada considerando o princípio da diversidade: na concepção cartesiana "não devemos considerar uma única criatura separadamente quando pesquisamos se asobras de Deus são perfeitas, mas de uma maneira geral todas as coisas em conjunto ${ }^{23}$ ".

21 DESCARTES. Carta à Mesland de 02 de maio de 1644. In: TEIXEIRA, S. C. A indiferença é um grau de liberdade. Multi-ScienceJournal, p. 28.

22 DESCARTES. Carta à Mesland de 02 de maio de 1644. In: TEIXEIRA, S. C. A indiferença é um grau de liberdade. Multi-ScienceJournal, p. 28.

23 DESCARTES, Meditação Quarta, p. 125. 
É no parágrafo $8^{24}$ da Meditação Quarta, que Descartes introduz o princípio da diversidade: sua tese é a de que Deus em Sua suma bondade, onipotência, onisciência, tudo pensa e cria, então o universo é o mais diverso possível. Não se trata de optar pelo que é bom, como já mencionamos, Deus simplesmente cria todas as coisas e porque é ele quem cria, que é efetivamente bom. Nesse contexto, considerando toda a diversidade criada por Deus, é que se justifica a existência dos seres que podem errar e erram, bem como seres que podem errar e não erram e os que não podem errar e não erram, de modo que há os seres que são livres e os que não são, por serem desprovidos de razão. Deus faz o que quer e o que faz, dada sua perfeição, é “perfeito e inteiramente acabado", afinal, diz Descartes que

se é verdade que, quanto mais um artesão é perito mais as obras que saem de suas mãos são perfeitas e acabadas, que ser imaginaríamos nós que, produzido por esse soberano criador de todas as coisas, não fosse perfeito e inteiramente acabado em todas as suas partes? ${ }^{25}$

Deus fez os homens errando e por sermos uma criação divina, somos perfeitos, ainda que isso seja concebido pelas criaturas pensantes como uma imperfeição. Ainda assim, na concepção cartesiana, não há razões para nos lastimarmos sobre o fato de sermos os seres que podem errar e erram: nossas faculdades são perfeitas nelas mesmas, pois a faculdade da vontade e a faculdade do entendimento operam exatamente como deveriam operar quando foram criadas por Deus e agem exatamenteconforme a vontade divina, como veremos adiante, e o universo, em sua totalidade, é perfeito como é.

O fato de sermos como somos é uma das perfeições das quais o universo é composto, pois fazemos parte da diversidade absoluta criada pela perfeição divina e é exatamente a diversidade absoluta que faz a perfeição, mas nós não compreendemos assim por sermos seres finitos. Portanto, a solução cartesiana para a questão metafísica relativa ao erro da substância pensante, resumidamente, consiste na tese de que ao criar toda a diversidade, Deus nos criou podendo errar e errando, por criar de maneira infinitamente diversa, sendo a perfeição exatamente a diversidade.

24 Descartes retoma seu argumento no parágrafo 15, na tradução de J. Guinsburg e Bento Prado Júnior (1973). AT VII: 61.

25 DESCARTES, Meditação Quarta, p. 124. 
A explicação da questão epistêmica para o erro, segundo Descartes, por sua vez, está num descompasso entre as faculdades da vontade e do entendimento. Nas palavras do filósofo, seus erros dependem:

(...) do concurso de duas causas, a saber, do poder de conhecer que existe em mim e do poder de escolher, ou seja, meu livre arbítrio; isto é, de meu entendimento e conjuntamente de minha vontade. Isto porque, só pelo entendimento, não asseguro nem nego coisa alguma, mas apenas concebo as ideias das coisas que posso assegurar ou negar ${ }^{26}$.

O erro seria então o resultado do descompasso entre a finitude do entendimento (que concebe ideias claras e distintas e ideias obscuras e confusas) e a infinitude da vontade. O entendimento é uma faculdade finita, porque não concebe ${ }^{27}$ todas as ideias (mas já vimos que o erro não é relativo às ideias que não temos) e porque das ideias que tem não são todas claras e distintas. Por apenas contemplar ${ }^{28}$ as ideias, a faculdade do entendimento não age em relação às ideias que concebe e, assim, não afirma ou nega absolutamente coisa alguma por ela mesma. Embora o entendimento seja finito e conceba tanto as ideias claras e distintas como as obscuras e confusas, “jamais encontraremos nele erro algum, desde que se tome a palavra erro em sua significação própria ${ }^{29 ” . ~ A l e ́ m ~ d o ~ f a t o ~ d e ~ q u e ~ o ~ e n t e n d i m e n t o ~ n a ̃ o ~ e r r a ~ p o r q u e ~ n a ̃ o ~ a f i r m a ~ n e m ~ n e g a ~}$ coisa alguma já que é uma faculdade passiva, Descartes ainda argumenta que se trata de uma faculdade perfeita em seu gênero, como toda faculdade criada por Deus, e, nesse sentido, por si só não pode levar ao erro. O entendimento é perfeito em seu gênero, porquefaz exatamente aquilo para o que foi criado por Deus, a saber, concebeideias.

Na análise epistêmica acerca do erro, Descartes examina também a faculdade da vontade, ou seja, a faculdade de julgar ideias afirmando ou negando e, assim, realizando um dos atos da vontade sobre as ideias. Também criada por Deus, elaé a faculdade da ação, isto é, ela tem a condição necessária para que aja - ou não-concretizando uma ação de forma livre. Diferentemente do entendimento, a faculdade da vontade

26 DESCARTES, Meditação Quarta, p. 125.

$27 \mathrm{O}$ ato de conceber, em Descartes, é passivo.

28 Somente no caso das ideias fictícias há uma distinção, visto que ao termos uma ideia fictícia não temos uma ideia inata. As ideias fictícias são compostas por nós, mas qualquer ideia que não seja fictícia não depende de nós e sim das coisas.

29 DESCARTES, Meditação Quarta, p. 125. 
é infinita na medida em que pode se aplicar a tudo que o entendimento lhe oferece. É exatamente por ser infinita que a vontade é livre. Descartes diz que a experimenta “tão vaga e tão extensa que ela não está encerrada em quaisquer limites ${ }^{30}$ ” e é exatamente por isso que a vontade é o que nos assemelha a Deus, conforme Descartes:por ser infinita e livre. No entanto, embora estruturalmente a vontade da substânciapensante finita seja de natureza infinita, está diretamente ligada ao entendimento, ou seja, a algo que é, efetivamente, finito. Aqui, então, temos um ponto problemático a ser considerado: afirmar que a vontade pode se aplicar a tudo, no caso da substância pensante finita, significadizer que ela pode ser aplicada tanto às ideias claras e distintas como também às obscuras e confusas. Nas palavras de Descartes:

(...) sendo a vontade muito mais ampla e extensa que o entendimento, eu não a contenho nos mesmos limites, mas estendo-a também às coisas que não entendo ${ }^{31}$; das quais, sendo a vontade por si indiferente, ela se perde muito facilmente e escolhe o mal pelo bem ou o falso pelo verdadeiro. O que faz com que eu me engane e peque ${ }^{32}$.

QuandoDescartes diz que a vontade "se perde muito facilmente e escolhe o mal pelo bem ou o falso pelo verdadeiro”, essa 'escolha' do mal pelo bem ou do falso pelo verdadeiro acontece porque a vontade pode se aplicar a tudo oque o entendimento mostra: quando o entendimento concebe as ideias, como já mencionamos, estas podem ser claras e distintas ou, ainda, obscuras e confusas. No que concerne ao erro que interessa a Descartes o que acontece é que o mal é tomado pelo bem ou o falso pelo verdadeiro, porque a substância pensante opta pelo que é obscuro e confuso, mas - e é isto que mais interessa para Descartes - acreditando efetivamente que a opção tomada havia sido por uma ideia clara e distinta, como veremos.

Isso acontece, porque mediante ao que lhe foi apresentado, a vontade atua livremente, independentemente de qualquer determinação ou coação externa, de maneira que a vontade escolhe por si mesma dar adesão ao que lhe aparece como claro e distinto, ainda que efetivamente não o seja. É porque há uma determinação interna (uma tendência natural e irresistível da vontade) que a vontade afirma, crê nas ideias claras

30 DESCARTES, Meditação Quarta, p. 126.

31 Obscuras e confusas.

32 DESCARTES, Meditação Quarta, p. 127. 
e distintas e a vontade é livre exatamente porque age de acordo com o que o entendimento mostra, assim se uma ideia aparece como clara e distinta a vontade tende irresistivelmente a afirmá-la. Se aparece como obscura e confusa a vontade imediatamente deveria suspender o juízo.O problema é que ideias obscuras e confusas as vezes aparecem como claras e distintas.

No que diz respeito à liberdade da vontade, Descartes afirma que:

(...) consiste somente em que podemos fazer uma coisa ou deixar de fazer (isto é, afirmar ou negar, perseguir ou fugir) ou, antes, somente em que, para afirmar ou negar, perseguir ou fugir às coisas que o entendimento nos propõe, agimos de tal maneira que não sentimos absolutamente que alguma força exterior nos obrigue a tanto. ${ }^{33}$

A expressão "antes", da citação acima, nos remete a duas definições de liberdade ligadas por esse termo. Na teoria da liberdade cartesiana há dois níveis de liberdade: a primeira é a liberdade em mais baixo grau, relacionada à liberdade como poder dos contrários (liberdade como livre-arbítrio), que pode afirmar ou negar conteúdos apresentados pelo entendimento, o que envolve um estado de indiferença da substância pensante que é livre para escolher entre dois opostos. Podemos compreender que, neste caso, para Descartes, a liberdade é acompanhada por um estado de indiferença, e não é levada pela percepção da verdade.

Descartes diz que quando não é:

absolutamente impelido para um lado mais do que para outro pelo peso de alguma razão, é o mais baixo grau de liberdade, e faz parecer mais uma carência no conhecimento do que uma perfeição na vontade ${ }^{34}$

Ele afirma que "se conhecesse sempre claramente o que é verdadeiro e o que é bom, nunca estaria em dificuldade para deliberar que juízo ou que escolha deveria fazer; e assim seria inteiramente livre sem nunca ser indiferente 35 ".

A segunda noção de liberdade é a que Descartes entende como liberdade plena (o grau mais alto de liberdade), quando a vontade age por uma determinação espontânea in-

33 DESCARTES, Meditação Quarta, p. 126.

34 DESCARTES, Meditação Quarta, p. 127.

35 DESCARTES, Meditação Quarta, p. 127. 
terna e necessária para o assentimento de uma ideia. A vontade com sua espontaneidade acentuada atua com seu poder de agir sem coação externa e ocorre a inclinação natural e irresistível (essencial fundamento da liberdade plena). Descartes defende não ser necessário que ele

(...) seja indiferente na escolha de um ou de outro dos dois contrários; mas antes, quanto mais (...) pender para um, seja porque (...) conheça evidentemente que o bom e o verdadeiro aí se encontrem, seja porque Deus disponha assim o interior do meu pensamento, tanto mais livremente o escolherei e o abraçarei $^{36}$.

O mais alto grau de liberdade (a liberdade plena) é quando o ato é determinado pela razão dando adesão irresistível (em função da força da razão) às ideias claras e distintas. Dessa forma a liberdade da substância pensante é tanto maior quanto maior for a inclinação. O mais alto grau de liberdade, por ser uma ação espontânea, faz com que os homens ajam sem coação externa, de forma que os atos da vontade (determinados pelo ato de perceber do entendimento) são livres em grau mais alto e a razão é autodeterminada.

Embora haja casos em que a substância pensante não tem razões suficientes na escolha entre dois opostos, no caso da liberdade plena o que se supõe é que diante de uma ideia clara e distinta o assentimento é imediato e incontestável. Quando vê algo com clareza e distinção, a substância pensante não opera fazendo escolhas e, dessa maneira, a liberdade funciona de tal forma que quando o entendimento mostra as ideias claras e distintas, irresistivelmente, por uma determinação interna, a partir do próprio entendimento, ocorre a adesão à tais ideias. E é nesse sentido que somos plenamente livres: porque pensamos e agimos de acordo com o nosso próprio entendimento.

A substância pensante, para Descartes, é indiferente perante as ideias quando se depara com razões favoráveis e contra as mesmas. Suspender o juízo sobre o que se pensa como obscuro e confuso evita o erro. Quando se tem ideias obscuras e confusas, percebe-se razões para o sim e para o não e é por isso que a substância pensante é indiferente nesses casos. Quando acontece de a substância pensante ter uma ideia obscura e confusa, percebida por ela como obscura e confusa, tendo em vista que ela própria não tem uma razão irresistível para uma determinada ação (afirmar ou 
negar), já que tem razões para afirmar e razões para negar a ideia em questão, a princípio, a substância pensante deve suspender o juízo acerca dela. Entretanto, nem sempre quando a substância pensante tem uma ideia obscura e confusa ela a percebe deste modo e por isso nem sempre ela suspende o juízo,então a substância pensante erra, segundo Descartes.

Quando a ideia aparece como clara e distinta, mesmo se for, na verdade, uma ideia obscura e confusa, a substância pensante irresistivelmente adere à mesma. Sobre este aspecto, podemos mencionar a explicação de Descartes, em conversa com Burman ${ }^{37}$. Nela o filósofo exemplifica uma situação prática, fornecendo o mesmo exemplo dado por ele na Meditação Sexta,a saber, o do homem hidrópico. Conforme Descartes,

(...) a secura da garganta pode, às vezes, não surgir como normalmente acontece, do fato de que uma bebida é necessária para a saúde do corpo, mas de alguma causa completamente oposta, como acontece no caso do homem com hidropisia ${ }^{38}$.

No exemplo acima, do homem com hidropisia, temos um caso em que a substância pensante percebe uma ideia como se fosse clara e distinta, a saber, a ideia de que 'sinto sede', ou seja, 'penso que' - percebo clara e distintamente que - meu corpo precisa de água. Desta ideia que foi percebida como clara e distinta, há a adesão irresistível,em função da crença advinda através de sede. O problema é que, nesses casos, essa percepção é obscura e confusa, porque a água fará mal ao corpo com hidropisia. A ideia

37 DESCARTES. Conversationwith Burman, 16 April 1648, p.346.

38 Com relação a questão metafísica(embora já tenhamos tratado sobre a mesma e, portanto, não pretendemos voltar a ela), cabe mencionar, sobre o exemplo do homem hidrópico, que para explicar a Burmano motivo de Deus nos ter feito podendo errar deste modo, sem que a alma tenha consciencia do erro dos sentidos, em vez de nos conpensar, ou seja,em vez de Deus nos criar de maneira que fossemos preservados da possibilidade do erro, em uma circunstância como essas, Descartes afirma que é melhor que o erro seja induzido eventualmente em uma ocasião assim do que sermos sempre induzidos ao erro quando o corpo está em boa saúde. Isso, porque nosso corpo é como uma máquina, para Descartes, e faz parte dos desígnios de Deus que o nosso corpo funcione como um instrumento de operação universal que atua sempre da mesma maneira. Assim, sempre ao estar em boa saúde, o corpo daria à alma uma consciência correta, mas doente o corpo afeta a alma de acordo com as leis universais estabelecidas por Deus, tendo em vista o seu modo específico de operar. Como resultado, diz Descartes a Burman, que há um estado da consciência pelo qual a alma é enganada. Desse modo, o corpo age enganando a alma, em casos como o exemplificado, por sempre agir de maneira universal, por suas leis universais.(DESCARTES. Conversationwith Burman, 16 April 1648). 
de que 'sinto' sede somente será clara e distinta se concebida como 'penso que' sinto sede, no caso de estar tipificando: 'penso, meu corpo precisa de água'. Ou seja, a ideia só é clara e distinta quando a sensação de sede é percebida como dizendo algo sobre o pensamento ('penso que meu corpo precisa de água’) e não sobre o corpo em questão.

Para tanto, ou seja, para percebermos que a ideia que temos é efetivamente clara e distinta, é preciso estar atento, conforme adverte Descartes, nos Princípios da Filosofia:

(...) Clara chamo àquela [percepção ${ }^{39}$ ] que está manifestamente presente a uma mente atenta, assim como dizemos que são claramente vistas por nós as [coisas] que, presentes a um olho que enxerga, movem-no de maneira suficientemente forte e manifesta. Distinta, porém, é aquela que, além de ser clara, é tão precisamente separada das outras que absolutamente nada mais contém em si além do que é claro ${ }^{40}$.

Mas estar atento é, como o próprio Descartes diz, uma tarefa complexa. Nos Princípios, o filósofo é cauteloso e alerta que há muitos homens que não conseguem formar nem mesmo um juízo corretodurante toda a vida, em suas palavras: “(...) [há] mesmo muitíssimos homens [que] em toda a sua vida jamais percebem coisa alguma de maneira suficientemente correta para formar um juízo certo acerca disso ${ }^{41}$ "

Assim, algumas vezes ideias obscuras e confusas aparecem à substância pensante como claras e distintas e,nesses casos,a substância pensante não suspende o juízo e tais ideias são afirmadas como verdadeiras. A substância pensantesegue uma tendência irresistível da vontade à ideia equivocada,porque a tomacomo clara e distinta. Assim, ao dar o assentimento irresistível à ideia obscura e confusa que aparece como clara e distinta, a substância pensante ao invés de suspender o juízo, erra.

Outro ponto importante na problematização do erro, na concepção de Descartes, está numa passagem já citada anteriormente, mas com pontos ainda importantes a serem mencionados, como veremos: Descartes diz sobre a vontade que sendo ela

39 Acréscimo nosso, de acordo com o início do parágrafo, na tradução, para melhor compreensão do leitor.

40 DESCARTES, Princípios da Filosofia, p. 61.

41 DESCARTES, Princípios da Filosofia, p. 61. 
(...) muito mais ampla e extensa que o entendimento, eu não a contenho nos mesmos limites, mas estendo-a também às coisas que não entendo ${ }^{42}$; das quais, sendo a vontade por si indiferente, ela se perde muito facilmente e escolhe o mal pelo bem ou o falso pelo verdadeiro. O que faz com que eu me engane e peque $^{43}$.

A questão epistêmica tem uma gramática distinta da questão moral: no primeiro caso, se supõe não saber que se está errando, já no segundo caso, parece acontecer o contrário, parece que se supõe saber estar errando. Como podemos observar, na citação acima, Descartes trata de ambos os erros, epistêmico e moral, como se fossem do mesmo âmbito, mas efetivamente talvez não seja. No entanto, neste momento, não vamos falar sobre isso, embora consideramosimportante mencionar que, com efeito, no Resumo da Quarta Meditação, o próprio Descartes diz que não tratará do erro moral ou do pecado, conforme suas palavras:

(...) é de notar que não trato de modo algum, neste lugar, do pecado, isto é, do erro que se comete na busca do bem e do mal, mas somente daquele que sobrevém no julgamento e no discernimento do verdadeiro e do falso; e que não pretendo falar aí das coisas que competem à fé ou à conduta da vida, mas somente daquelas que dizem respeito às verdades especulativas e conhecidas por meio da tão-só luz natural44

Ainda assim, embora tenha dito que não trataria sobre o pecado, como vimos, no próprio texto da Quarta Meditação, por alguma razão, Descartes acaba falando. Uma possível explicação para essa atitude de Descartes é a recomendação de Arnauld, nas Quartas Objeções: Arnauld recomenda que Descartes não trate do erro moral, visando não irritar os jesuítas. Ele diz que Descartes deveria indicar na sinopse, ao abordar a Quarta Meditação, ou no texto da mesma, uma advertência aos leitores que quanto à investigação da causa do erro, ali seria abordado primordialmente “(...) [o]s erros cometidos ao distinguir entre o verdadeiro e o falso, e não aqueles que ocorrem em nossa busca do bem e do mal45". Para Arnauld, falar acerca dos segundos geraria grandes objeções e, diante disso, seuconselho,para Descartes, é que lhe parece "que a prudência

\footnotetext{
42 Obscuras e confusas.

43 DESCARTES, Meditação Quarta, p. 127.

44 DESCARTES, Resumo, p. 89.

45 ARNAULD, Fourth set ofobjections, AT VII: 215, p. 151.
} 
exige, e a ordem de exposição a que o nosso autor é tão dedicado exige, que qualquer coisa que não seja relevante e que possa dar origem a controvérsia seja omitida ${ }^{46}$."

No entanto, Descartes, apesar das orientações de Arnaul, como vimos, fala sobre engano e pecado, e assim podemos notar que ele aborda tanto o erro epistêmico quanto o erromoral. Acerca do último, ele confessa na carta à Mesland, de 02 de maio de 1644 , que

(...) em todo evento onde há ocasião de pecar há indiferença; e não creio que, para fazer o mal, seja necessário ver claramente que o que nós fazemos é ruim; é suficiente ver confusamente, ou somente de se lembrar que se julgou outrora que aquilo o fosse, sem o ver em nenhuma maneira, isto é, sem se ater às razões que o provam; pois, se nós o víamos claramente, nos seria impossível pecar durante o tempo que nós o víamos desse modo; é por isso que se diz omnis peccans est ignorans [Todo homem que peca é um homem que ignora]. ${ }^{47}$

Segundo Descartes, portanto, nós não fazemos o mal tendo clareza de que estamos fazendo o mal. É porque temos ideias confusas e deliberamos com base em lembranças de julgamentos passados, sem efetivas provas,que ocorre o erro. Nós não somos infalíveis e nossa vontade é tal que segue intensamente a luz do intelecto que crê numa ideia equivocada, porque o intelecto, que é a própria razão, atua mediante a operação da vontade e do entendimento: quando uma ideia parece verdadeira, ou seja, quando o entendimento apresenta uma ideia que é assentida como verdadeira pela vontade, o intelecto (que envolve a vontade e o entendimento) acaba crendo na ideia equivocada quando erramos.Quando a vontade assente às ideias claras e distintas, acerta e tem um juízo verdadeiro, no entanto quando adere às ideias obscuras e confusas ocorre o mal que é o erro.

Diante deste outro aspecto, em que não temos apenas o erro epistêmico, mas também o moral, outra possibilidade, conforme aponta Descartes para Mesland, na busca de sermos bem-sucedidos ao evitarmos o erro, está na graça, que também evita (no caso de ideias obscuras e confusas) a efetiva indiferença, pois "ela [a graça] nos faz pender mais para um lado que para o outro ${ }^{48}$ " diminuindo a indiferença, mas não diminuindo a liberdade. Nesse contexto, o que acontece

46 ARNAULD, Fourth set ofobjections, AT VII: 215-216, p. 151.

47 DESCARTES. Carta à Mesland de 02 de maio de 1644. In: TEIXEIRA, S. C. A indiferença é um grau de liberdade. Multi-ScienceJournal, p. 28.

48 DESCARTES. Carta à Mesland de 02 de maio de 1644. In: TEIXEIRA, S. C. A indiferença é um grau de liberdade. Multi-ScienceJournal, p. 28. 
é que a razão nos dá ideias e a graça nos revela verdades sobre as coisas e, quando se conhece pela graça, se conhece igualmente clara e distintamente tal qual ocorre quando se conhece pela razão.

\section{CONCLUSÃO}

Na questão epistêmica acerca da problematização do erro, ter a faculdade da vontade não significa que se possa ter o controle total das ações, mas que a substância pensante tem uma faculdade distinta da faculdade de conceber e que é a responsável pelas ações dos seres racionais. Por ser ativa, não significa que seja possível controlá-la. Os atos da vontade da razão são sempre determinados pela forma como o entendimento percebe algo. Os atos da vontade, que por serem livres acontecem sem coação externa, dependem do modo como a ideia é concebida pelo entendimento. Assim, esses atos da vontade estão sujeitos à determinação do que é exibido no intelecto pelo entendimento, que leva a substância pensante a escolher o mal pelo bem ou o falso pelo verdadeiro, no caso em que as ideias obscuras e confusas são apresentadas comoclaras e distintas. Nesse contexto, a liberdade da vontade se dá pelo fato de esses atos serem determinados tão somente pela razão, como mencionado, sem coação externa, pois é a razão que toma a decisão de suspender o assentimento. Trata-se, então, de uma determinação interna da razão, que é livre exatamente porque não há coação externa, sendo ela própria que toma a decisão de suspender o assentimento ou de dar a adesão.

Embora o erro, considerando a ação dos homens, seja uma possibilidade efetiva, Descartes defende que é próprio da substância pensante nunca querer julgar equivocadamente.Nos Princípios, ele explica que

como sabemos que todos os nossos erros dependem da vontade, pode parecer admirável que alguma vez nos enganemos, pois não há ninguém que queira enganar-se. Mas são coisas muito diversas querer enganar-se e querer assentir àquilo em que eventualmente se encontra um erro. E embora, na verdade, não haja ninguém que queira expressamente enganar-se, dificilmente, porém, haverá alguém que não queira muitas vezes assentir àquilo no qual, sem que ele saiba, está contido um erro. E até mesmo o próprio desejo de alcançar a verdade faz muitíssimas vezes com que os que não sabem corretamente por qual manei- 
ra ela deva ser alcançada façam um juízo sobre aquilo que não percebem e, por isso mesmo, [faz] com que errem ${ }^{49}$.

São ações absolutamente distintas “querer enganar-se e querer assentir àquilo em que eventualmente se encontra um erro". A problemática aqui envolvida está relacionada a assentir ideias obscuras e confusas tomadas como claras e distintas, considerando o desejo de alcançar a verdade por parte de quem faz um juízo equivocado ao não saber corretamentecomo se deve alcança-la.O ponto que interessa a Descartes é esclarecer que a substância pensante assente a ideia cujo erro está contido, dado descompasso entre as faculdades da vontade e do entendimento, mas absolutamente sem saber que há um erro ali envolvido, de modo que a ideia obscura e confusa é aderida, sem que se saiba, porque aparecia como clara e distinta.

O descompasso na maneira como as faculdades da substância pensante operam e os erros advindos do mesmo, todavia, conforme explica Descartes, na Quarta Meditação, não acarreta necessidade alguma para nos lastimarmos do fato de Deus, ao colocar os homens no mundo,os tenha criado assim. Para ele, não há porque nos lastimarmos de não termos sido postos "na ordem das coisas mais nobres e das mais perfeitas 50", porque, diz o filósofo:

se ele [Deus] não me concedeu a virtude de jamais falhar através do meio (...) que depende de um claro e evidente conhecimento de todas as coisas a respeito das quais posso deliberar, ele ao menos deixou em meu poder o outro meio, que é reter firmemente a resolução de jamais formular meu juízo a respeito de coisas cuja verdade não conheço claramente. Pois, embora eu note essa fraqueza em minha natureza, de não poder ligar continuamente meu espírito a um mesmo pensamento, posso, todavia, por uma meditação atenta e amiúde reiterada, imprimi-la tão fortemente na memória, que não deixe jamais de lembrar-me, todas as vezes que tiver necessidade, e adquirir, desta maneira, o hábito de nunca falhar ${ }^{51}$.

Sempre que necessário, nos lembramos, através da nossa forte memória dada por Deus, quequeremos nunca julgar errado e com isso podemos adquirir o hábito (que precisamos buscar por toda a vida) de não falhar. Ainda assim, não temos o efetivo

49 DESCARTES, Princípios da Filosofia, p. 61.

50 DESCARTES, Meditação Quarta, p. 129.

51 DESCARTES, Meditação Quarta, p. 129. 
poder de não errar, pois evitar não significa erradicar o erro, isto porque a busca pelo hábito de nunca falhar não pode dar conta de afetara operação de nossas faculdades: devido a finitude da substância pensante, sempre haveráa possibilidade de se assentir à ideias obscuras e confusas que aparecem como claras e distintas, estando ela sempre propensa ao erro. Evitar o erro, adquirindo o hábito da busca constante por não falhar não é o mesmo que erradicar o erro da vida humana, afinal dado descompasso entre as faculdades da vontade e do entendimento ser efetivado, porque ambas as faculdades agemexatamente do modo como foi decretado por Deus, a busca por não falhar nunca concretizaráo fim do erro.

O que Deus nos deu foram formas para buscar evitar o erro, ao utilizarmos a faculdade de julgar, no que concerne a questão epistêmica, mas dada diversidade (questão metafísica) como condição de um mundo perfeito criado por Deus, o erro também é necessário, nesse âmbito, na compreensão cartesiana.Metafisicamente, somos os seres que podem errar e erram, o quecompõe, junto aos outros seres, criados por Deus, a diversidade total que envolve a perfeição.Acreditamos que a questão epistêmica e a metafísica sejam explicações que além de compatíveis também são complementares na análise cartesiana acerca da problematização do erro. Nesse contexto, os atributos da bondade e da justiça divina não visam em especial aos homens, para Descartes, de maneira que é possível apenas ser excluídaa possibilidade do erro sistemático, mas não é possível eliminar a hipótese do erro em relação a essas criaturas.

\section{REFERÊNCIAS BIBLIOGRÁFICAS}

BATISTA, Geisa Mara e CARRARA, Daniel. A carta a Mesland de 9 de fevereiro de 1645: tradução e comentários.KRITERION, Belo Horizonte, nº 117, V. 49Jun./2008.

COTTINGHAM, John. Dicionário Descartes. Tradução de Helena Martins. Rio de Janeiro: Jorge Zahar Editor, 1995.

DESCARTES, René. Meditações. In: Os pensadores. Tradução de J. Guinsburg e Bento Prado Júnior. São Paulo: Ed. Abril, 1973.

DESCARTES, René. Princípios da Filosofia. Tradução de Guido Antônio de Almeida (coordenador), Raul Landim Filho, Ethel M. Rocha, Marcos Gleizer e Ulysses Pinheiro. Rio de Janeiro: Editora UFRJ, 2002. 
DESCARTES, René. Textos de Descartes sobre a livre criação das verdades eternas. Tradução de Marcos André Gleizer.Analytica, nº 1 e 2, V. 16, 2012.

DESCARTES, R. The PhilosophicalWritingsof Descartes. Volume II. The correspondence. Tradução de John Cottingham, Robert Stoothoff eDugald Murdoch. Cambridge: Cambridge University Press, 1991.

DESCARTES, R. The PhilosophicalWritingsof Descartes. Volume III. The correspondence.Tradução de John Cottingham, Robert Stoothoff, Dugald Murdoch e Anthony Kenny. Cambridge: Cambridge University Press, 1991.

ROCHA, Ethel Menezes. Criador perfeito e criaturas que erram. Analytica, $\mathrm{n}^{\mathrm{o}}$ 2, V. 7 , 2003.

ROCHA, Ethel Menezes. Indiferença de Deus e o mundo dos humanos segundo Descartes. Curitiba: Kotter Editorial, 2016.

TEIXEIRA, Suellen Caroline. A indiferença é um grau de liberdade. Multi-Science Journal, $\mathrm{n}^{\mathrm{o}} 1, \mathrm{~V} .1,2015$. 